\title{
Overloading Vehicle Impact Analysis on the Performance of Toll Road Traffic
}

\author{
Deni Setiawan*, Tri Tjahjono \\ Faculty of Engineering, Universitas Indonesia, Depok, Indonesia \\ *Corresponding author: setiawan_denia@yahoo.co.id
}

\begin{abstract}
Transportation of goods using landline is still the main choice of business in Indonesia. To reduce logistics costs, some businesses often add cargo to freight vehicles so that they exceed the specified standard conditions. Heavy vehicles have low speeds on a toll road and this has a negative impact on other road users. Due to the presence of heavy vehicles, travel time increases. This study will analyze the negative impact of the presence of heavy vehicles that have overloaded (Overloading) on a toll road. The method used is derived from the Indonesian Highway Capacity Manual (MKJI) to calculate the traffic characteristics such as speed, volume, and degree of saturation as well as using the Highway Development and Management (HDM) 4 for vehicle consumption model. The results obtained showed heavy vehicle speed decreases as the load increases so the speed of traffic carried by the heavy vehicle overloading conditions lower than the speed of heavy vehicles with cargo load conditions according to the capacity. The linear regression equation between Speed to percentage overload is $\mathrm{y}=$ $-11.018 x+46153$. Operating costs of heavy vehicles under higher overload conditions when compared to heavy vehicles with normal load conditions.
\end{abstract}

Key words : Impact, Heavy vehicle, Overloading, MKJI, HDM-4, Toll road, Vehicle operating costs.

\section{INTRODUCTION}

Transportation of goods using landline is still the main choice of business in Indonesia. This phenomenon happens because other alternative modes are inadequate in providing door to door services. In order to reduce logistics costs, some businesses often add cargo to freight vehicles so that they exceed the specified standard conditions. By implementing this method, businesses can earn more benefit in the short term. However, in practice, it is not uncommon that overloaded heavy vehicles that pass through the toll road are efficiency refers to realizing improved services and economic growth in the region.
One of the approaches done by the Ministry of Transportation to reduce the existence of overloaded vehicle is by using weighbridge. Weighbridge is done in order to ensure the safety of the traffic, to keep track of overloaded vehicle, and to prevent any damages caused by overloaded vehicle. Regional Government Regulation Number 23 year 2014 stated that Ministry of Transportation is the one responsible to manage and strictly supervise the operation of weight bridges. But in reality, weight bridges seem to become a place for illegal levies by irresponsible people. This means, instead of making vehicle overloading completely illegal, overload vehicle is only going to be charged with an extra fee by giving tolerance of overload vehicle up to $70 \%$. This means that heavy vehicles are allowed to bring load of more than $70 \%$ than its initial allowable load. Thus, the function of weighbridges becomes less effective than its initial purpose.

The existence of heavy vehicles that have a low speed on the toll road if the negative effect on other road users. As a result of the presence of these heavy vehicles, travel time becomes increased. Overloaded vehicles produced higher kinetic energy, which resulting in greater impact forces and damages to other vehicles or infrastructure [1]. Especially when involved in an accident, the impacts are more likely to be fatal. Therefore, this research will analyze the impact of heavy vehicles that have excess loading on the traffic performance on the Toll Road.

One of the toll roads that have an important role in the rotation of the Indonesian economy is the Jakarta-Cikampek Toll Road. This toll road connects the city of Jakarta which is the center of the economy with the industrial area of West Java Province. According to Jasa Marga data in 2018, there are around 110 thousand trucks that cross the Jakarta-Cikampek toll road every day. The overloaded vehicle will adversely affect the performance of the Jakarta-Cikampek Toll Road. The Ministry of Transportation stated that up to $76 \%$ of the heavy vehicle that passed on the Jakarta-Cikampek Toll road are overloaded, which makes them move slowly and caused congestion. The initial travel time from Jakarta to Bandung, which distance is $140 \mathrm{~km}$, is only three hours. However, nowadays the travel time could take up to 6 hours because of the congestion. 
Deni Setiawan et al., International Journal of Emerging Trends in Engineering Research, 8(7), July 2020, 4828 - 4833

\section{LITERATURE REVIEW}

Based on Government Regulation No. 15 of 2005, toll roads are public roads that are part of the road network system and national road users are required to pay certain fees. In this study, the writer will focus on the Jakarta-Cikampek toll road. This toll road was inaugurated in 1988. Until this research was conducted, it is $73 \mathrm{~km}$ away from the Jakarta-Cikampek toll road and is operated by PT Jasa Marga Tbk.

There are several studies that have been carried out on the impact of heavy vehicles both under normal circumstances and overloaded on the road network. The short-term effect of implementing a vehicle overloading ban shows a positive impact because (1) it reduces the cost of transporting goods tons per kilometer even though vehicle operating costs per kilometer is increase, (2) increased competition sesame haulage company which in turn give benefit to consumers, (3) increase the profit, and (4) reduce the number of trips taken and kilometers travelled.In several other studies show the negative impact of the presence of heavy vehicles. The presence of heavy vehicles or trucks has an impact on slowing the speed, congestion, and road capacity [2]. Moreover, heavy vehicles can not be separated from the problem of traffic accidents. Heavy vehicles are considered as the main cause of traffic accidents due to the increase in the volume of heavy vehicles [3]. The proportion of accidents suffered by heavy vehicles or trucks is $50-75 \%$ of the total accidents that occur in urban areas [4]. This is also supported by the results of research that says the presence of excessive heavy vehicles (overloading) increases the likelihood of accidents by up to $5 \%$ [5].

Overloading of heavy vehicles also have a close relationship with damage to the road surface. It contributes as much as more than $50 \%$ to pavement failure [6]. Without further approaches to prevent it, the continuous use of overloaded vehicle is harmful for pavement preservation. The normal condition of the cumulative crushing power is 1,555,777 ESAL but the power will increase to 3,153,079 ESAL because the vehicle is overloaded through the road. The age of Lamongan Gresik roads decreased to 4.93 years. Another impact of overloaded vehicles is the tensile strain of 292.4 and compressive strain of 322.2 micro strains (based program KENPAVE) that can reduce pavement design life of up to $96.78 \%$ to $96.85 \%$ and the cracking criterion to criterion groove.Extending the reference, the interaction on vehicle and impact and impact itself can be found in [7], [8], and [9].

In this study, vehicles were classified into 2 classes of rigid and articulated and the object of the study was collected into 7 types of vehicles in which Rigid 3 types, Articulated 4 types.

\section{RESEARCH METHODOLOGY}

\subsection{Determine of Main Variables (Determination of The Area and Time of Study)}

Some of the main variables used in this study are the average speed of vehicles, the proportion of overloaded vehicles, excess vehicle speed, and the and the percentage of the excess load. The specified location is the Jakarta-Cikampek toll road (KM 54 to KM 64). The time of data collection starts from September 2018 to June 2019.

A traffic counting and speed survey was conducted in the rest area of the Jakarta-Cikampek Toll Road ( $\mathrm{km} \mathrm{57)} \mathrm{using} \mathrm{a}$ speed cam. While the overloading vehicle survey was carried out on the Toll Road portable weighbridge Jakarta-Cikampek (km 59).

\subsection{Determination of Supporting Variable}

Supporting variables used are highway capacity, free-flow speed, degree of saturation, traffic volume, road gradients and geometries, number of lanes, and the length and width of the road.

\subsection{Data Collection and Data Processing}

Data collection was conducted to obtain primary data (Traffic Counting) and secondary data. The collected data were processed using the Indonesian Highway Capacity Manual (MKJI) 1997 and the method of Fuel Consumption Model of Highway Development and Management (HDM) 4.

Table 1: Results of data collection Jakarta-Cikampek toll road

\begin{tabular}{|c|c|c|c|c|c|c|c|}
\hline Type & $\begin{array}{c}\text { Kg Mean } \\
\text { Weight }\end{array}$ & Kg Min & Kg Max & $\begin{array}{c}\text { Avg \% } \\
\text { Overload }\end{array}$ & $\begin{array}{c}\text { Avg Spot } \\
\text { Speed }\end{array}$ & $\begin{array}{c}\text { Spot Speed } \\
\text { Min }\end{array}$ & $\begin{array}{c}\text { Spot Speed } \\
\text { Max }\end{array}$ \\
\hline 1 & 9940 & 3170 & 23920 & $34 \%$ & 41.83 & 23 & 58 \\
\hline 2 & 14437 & 2780 & 27850 & $35 \%$ & 39.12 & 24 & 69 \\
\hline 3 & 11627 & 3250 & 23820 & $28 \%$ & 41.18 & 19 & 61 \\
\hline 4 & 5951 & 670 & 22730 & $11 \%$ & 50.02 & 23 & 76 \\
\hline 5 & 10565 & 1040 & 27090 & $18 \%$ & 46.58 & 21 & 76 \\
\hline 6 & 8891 & 5810 & 15500 & $0 \%$ & 45.44 & 31 & 53 \\
\hline 7 & 13442 & 2000 & 25230 & $4 \%$ & 41.79 & 26 & 65 \\
\hline
\end{tabular}


Deni Setiawan et al., International Journal of Emerging Trends in Engineering Research, 8(7), July 2020, 4828 - 4833

\section{RESULTS}

The data collected is presented in

Table 1 . Results from all recorded data show the lightest and heaviest weight of the vehicle and the vehicle with the lowest to highest speed.

\section{ANALYSIS OF RESULTS}

Figure 1(a) shows a graph of the relationship between multiple overloading the vehicle speed. Figure 1(b) shows a graph of rigid heavy vehicles while Figure 1(c) shows a graph of the articulated vehicle.

Based on the third graph, the entire vehicle will produce inverse relationship. The resulting equation include rigid vehicle $y=-6.1794 x+42.75$ with $R^{2}=0.1433$, articulated vehicles $\mathrm{y}=-13.817 \mathrm{x}+46811$ with $\mathrm{R}^{2}=0.1265$ and $\mathrm{a}$ combination of all available data is $y=-11.018 x+46153$ with $\mathrm{R}^{2}=0.1318$.

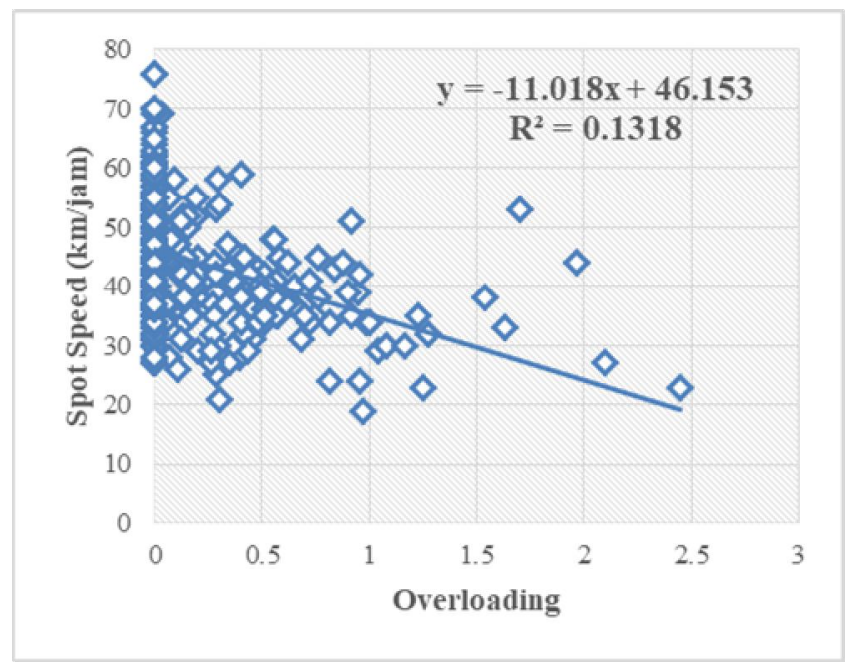

(a)

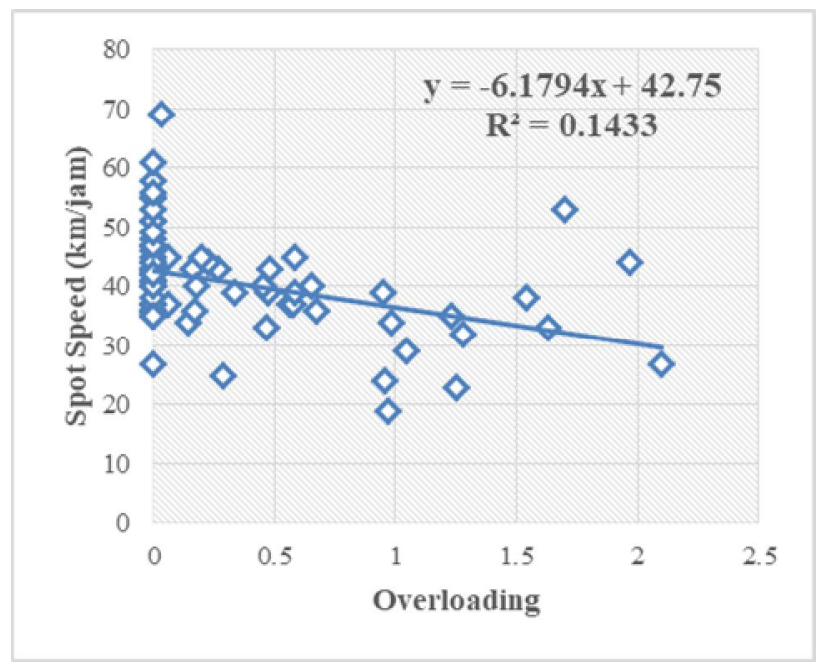

(b)

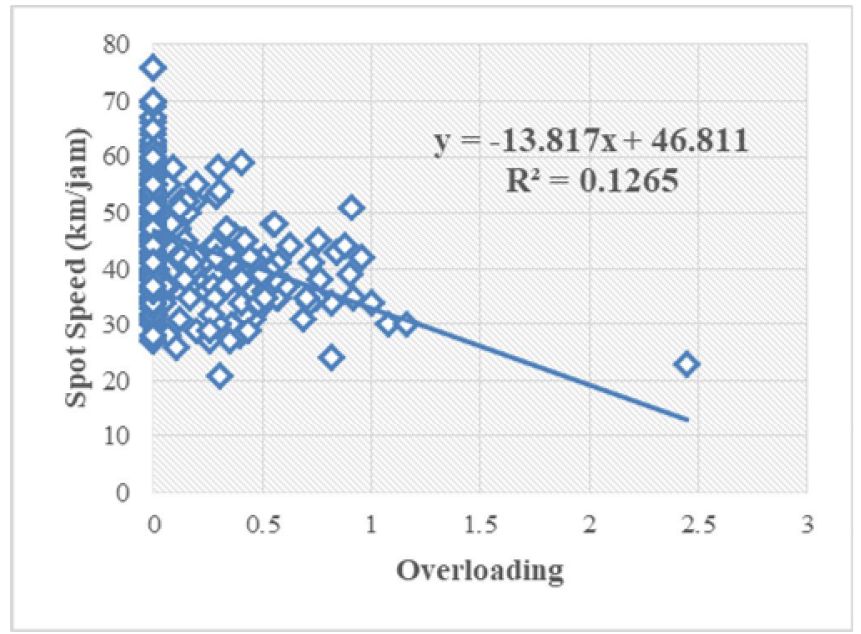

(c)

Figure 1: (A) Relationship between multiples overloading with vehicle speed on the entire vehicle weight ; (B) Rigid vehicle ; and (C) Articulated vehicle

In the case of a rigid vehicle, with y is the average speed of the vehicle while $\mathrm{x}$ is a multiple overloaded loaded than the weight of the vehicle. The model explains that at the time of the normal state (overload $=0$ ) then the average speed of vehicles is $42.75 \mathrm{~km} / \mathrm{h}$. Value of - 6179 stated decreased speed overload any increase by 1 unit.

$\mathrm{R}^{2}$ value indicates the level of accuracy of the model to the data distribution. The maximum value of $\mathrm{R}^{2}$ is 1 which means that $100 \%$ of the data distribution can be represented through the resulting model. In rigid vehicles, the $\mathrm{R}^{2}$ value is 0.1433 , which means that the model only represents $14 \%$ of the available data while the remaining $86 \%$ of other data cannot be drawn through the regression model. The same thing can also be seen from articulated vehicles and all vehicles with $\mathrm{R}^{2}$ value of 0.1265 and 0.1318 which represent $12.6 \%$ and $13.18 \%$ data distribution.

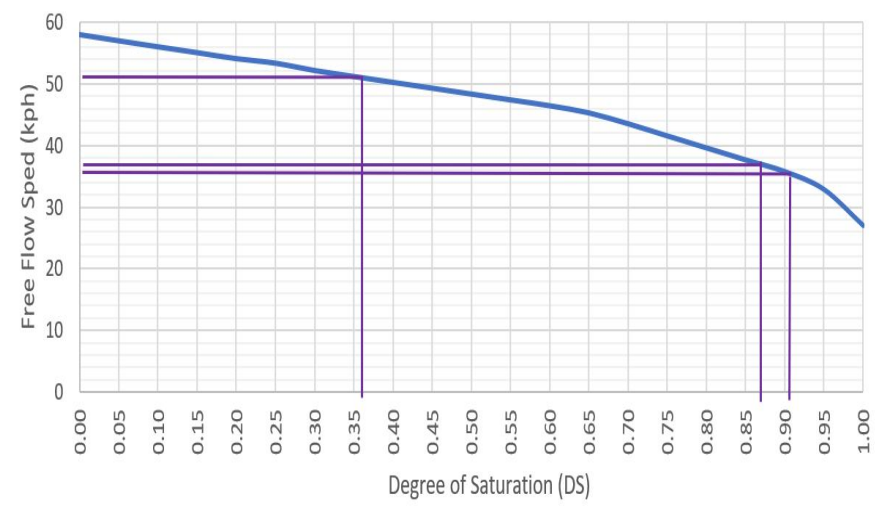

(a) 


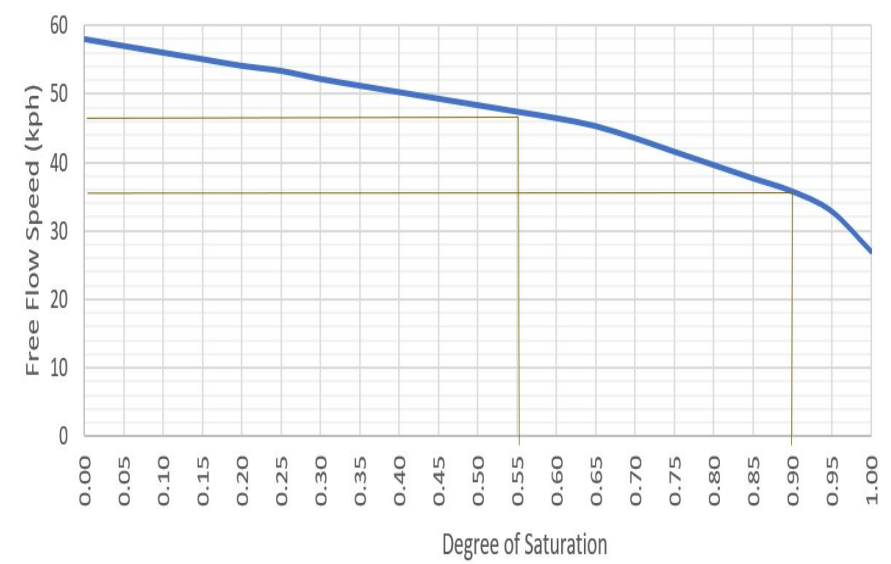

(b)

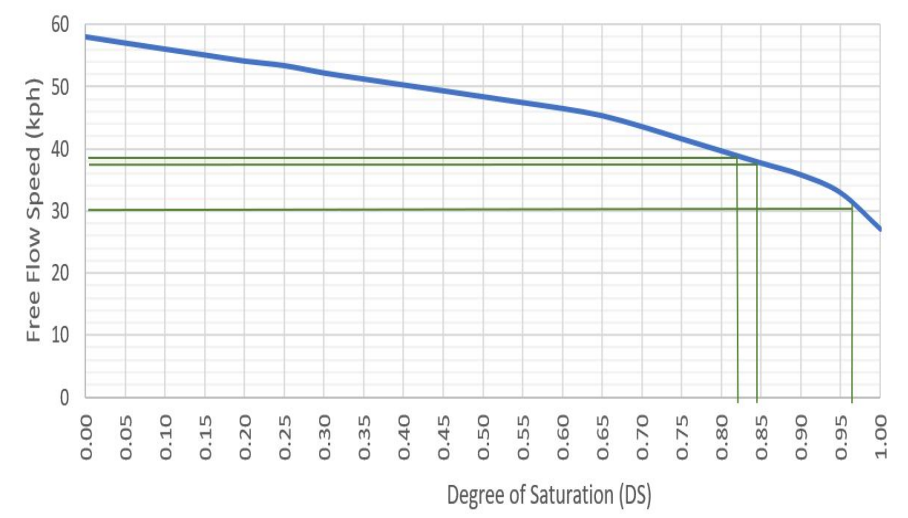

(c)

Figure 2: (a) Connection speed to the degree of saturation (DS) Vehicle group II; (b) Group III; and (c) Group IV \& V

Table 2: Vehicle speed and degree of saturation

\begin{tabular}{|c|c|c|c|}
\hline \multirow{2}{*}{$\begin{array}{l}\text { Vehicle } \\
\text { Group } \\
\end{array}$} & \multicolumn{3}{|c|}{ Speed $(\mathbf{k m} / \mathbf{h})$} \\
\hline & $\mathrm{x}<0 \%$ & $0<x<50 \%$ & $\begin{array}{c}50 \%<x< \\
100 \%\end{array}$ \\
\hline \multicolumn{4}{|l|}{ Group II } \\
\hline Speed & 50.86 & 37.77 & 36.77 \\
\hline $\begin{array}{l}\text { Degree of } \\
\text { Saturation }\end{array}$ & 0.03 & 0.87 & 0.91 \\
\hline \multicolumn{4}{|l|}{ Group III } \\
\hline Speed & 47.76 & 35.95 & 0 \\
\hline $\begin{array}{l}\text { Degree of } \\
\text { Saturation }\end{array}$ & 0.04 & 0.9 & - \\
\hline \multicolumn{4}{|l|}{$\begin{array}{c}\text { Group IV } \\
\& \text { V }\end{array}$} \\
\hline Speed & 38.55 & 37.95 & 31.48 \\
\hline $\begin{array}{l}\text { Degree of } \\
\text { Saturation }\end{array}$ & 0.83 & 0.85 & 0.97 \\
\hline
\end{tabular}

In the subsequent analysis phase only three categories. Vehicle groups IV \& V are combined because it has many similarities) which will be used further because the amount of data from other groups was not significant. All three graph shows the same thing. When the vehicle is subjected to overload the average speed of the vehicle is decreased. It is closely related to the percentage of the load and class vehicles carrying such cargo. As a result of the decrease in the speed of the degree of saturation of these roads will continue to rise toward 1 or nearly reached the capacity of the road.

The third chart has a similar pattern where there is a significant increase in the degree of saturation line with the increase in the load carried by the vehicle. Vehicle Group II and Group III showed a significant increase of the normal load $(0 \%)$ to $50 \%$, the degree of saturation of both these groups increased by around $50 \%$. in group II, the degree of saturation increased value of 0:36 into 0.87 whereas in group VIII of the increase occurred from 0:55 into 0.90. While the vehicle Group IV \& V degree of saturation increase in the load of $0 \%$ to $50 \%$ is not too big that is only 0.83 becomes 0.85 . However, the vehicle class IV \& V has the greatest degree of saturation values when carrying a load of $100 \%$ of the maximum capacity is 0.97 or close to $100 \%$ of the capacity of roads.

In the present study, a condition that occurs not normal conditions but assuming a platoon of heavy vehicles which resulted in another vehicle speed is interrupted or limited by the presence of heavy vehicles. Following the graph of speed with the degree of saturation as illustrated in Figure 2, the value of free-flow speed or the free flow value is limited to a maximum speed of heavy vehicles. The vehicle speed and the degree of saturation are shown in Table 2.

Fuel Consumption in the calculation model, the variables that include engine efficiency in fuel consumption, horsepower efficiency, maximum power that can be issued by the vehicle, as well as internal forces that have been converted to total power. Vehicle efficiency will be decreased along with an increase in the vehicle group. Value Ptot is the total power needed to move the vehicle. The larger the group of vehicles and loads that are loaded will be even greater power is required.

At the end of the calculation can be seen that Group IV and V would cost the largest fuel consumption than any other group and added burden loaded overload up to $100 \%$, the final value generated is $\mathrm{Rp} 4600 / \mathrm{km}$. while class II vehicles under normal conditions will require $\mathrm{Rp} 958$ / km. of these results and look at the graph when the vehicle is used on a toll road from Jakarta-Cikampek the more remote operated vehicle, the greater the operating costs to be incurred.

The final result of vehicle fuel consumption (Table 3) shows that the burden of overloading has a considerable influence on fuel consumption. The greater the load carried by the vehicle will increase the vehicle's fuel consumption, as seen in Figure 3. On the other hand, the larger class of vehicles also have an impact on fuel consumption 
Deni Setiawan et al., International Journal of Emerging Trends in Engineering Research, 8(7), July 2020, 4828 - 4833

The results of vehicle operating costs can be used by vehicle owners to consider the consequences of overload. On the one hand, overloading can benefit the vehicle owner by reducing the number of trips so that it is expected to reduce vehicle operating costs. But on the other hand, overloading also has a negative effect on operational costs because the more burden that exceeds capacity, the greater the operational costs incurred even in extreme conditions can reach double. On another aspect, overloaded vehicles can also endanger other vehicles, especially when crossing a ramp so that it adds to the negative impact of overloading.

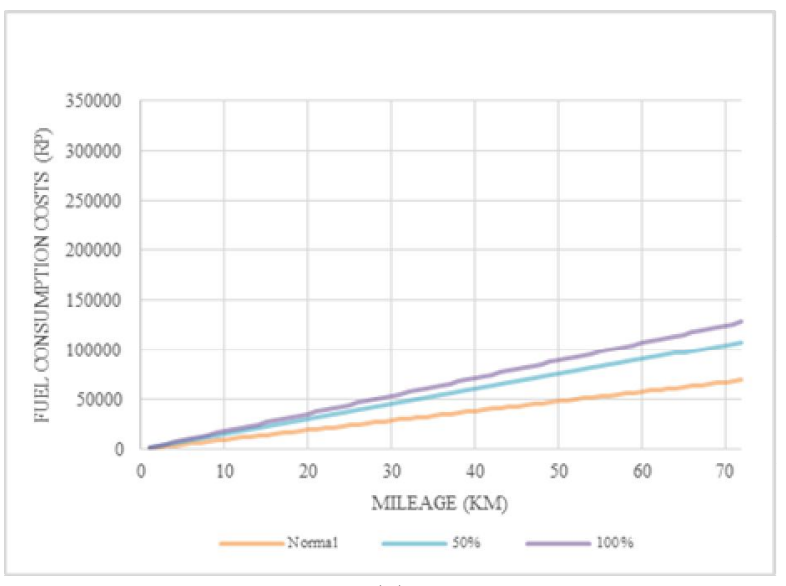

(a)

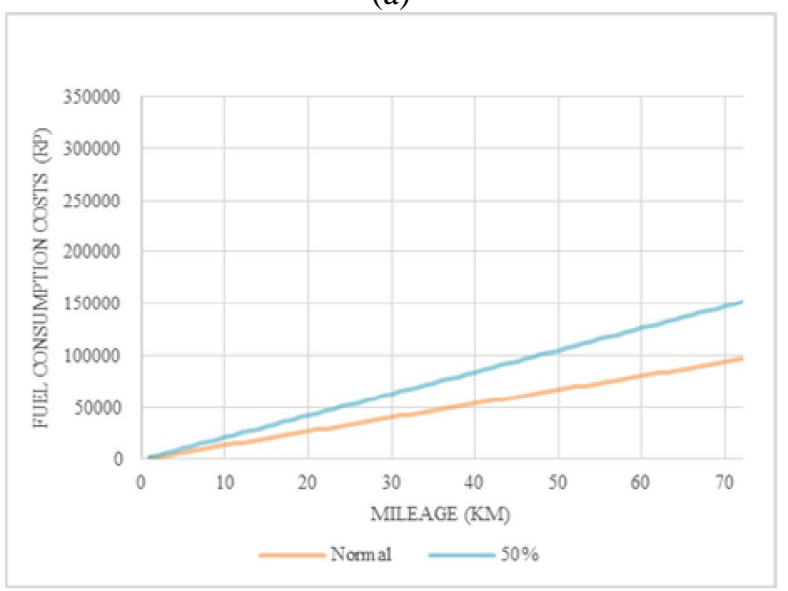

(b)

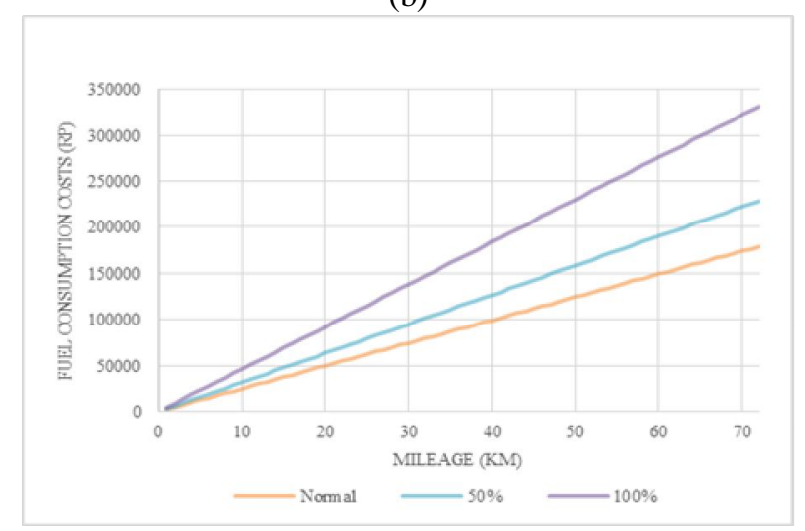

(c)

Figure 3: (a) Cost of Vehicle Fuel Consumption Group II (b) Class III (c) Class IV \& V
Table 3: Calculation model vehicle fuel consumption

\begin{tabular}{|l|c|c|c|c|c|c|}
\hline & $\begin{array}{c}\text { Group } \\
\text { II }\end{array}$ & $\mathbf{5 0 \%}$ & $\begin{array}{c}\mathbf{1 0 0} \\
\mathbf{\%}\end{array}$ & $\begin{array}{c}\text { Group } \\
\text { III }\end{array}$ & $\mathbf{5 0 \%}$ & \\
\hline P tot & 0.78 & 0.92 & 24.94 & 25.58 & 30.23 & $\mathrm{~kW}$ \\
\hline qv & 0.59 & 0.45 & 0.43 & 0.56 & 9.99 & $\mathrm{~m} / \mathrm{s}$ \\
\hline FC & 81.5 & 127.8 & 151.4 & 113.7 & 178.6 & $\mathrm{~mL} / \mathrm{km}$ \\
\hline VOC & 958 & 1501 & 1779 & 1336 & 2098 & USD $/ \mathrm{km}$ \\
\hline
\end{tabular}

\begin{tabular}{|l|c|c|c|c|}
\hline & $\begin{array}{c}\text { Group } \\
\text { IV } \\
\text { V }\end{array}$ & $\mathbf{5 0 \%}$ & $\begin{array}{c}\mathbf{1 0 0} \\
\mathbf{\%}\end{array}$ & \\
\hline P tot & 38.06 & 48.13 & 58.02 & $\mathrm{~kW}$ \\
\hline qv & 10.69 & 0.45 & 8.74 & $\mathrm{~m} / \mathrm{s}$ \\
\hline FC & 211.6 & 269.8 & 391.5 & $\mathrm{~mL} / \mathrm{km}$ \\
\hline VOC & 2486 & 3170 & 4600 & $\mathrm{USD} / \mathrm{km}$ \\
\hline
\end{tabular}

\section{CONCLUSION}

The proportion of vehicle overloading is inversely proportional to the average speed of the vehicle. Increasing the proportion of overloading of vehicles on a road section will reduce the average speed of other vehicles as well as increasing the degree of saturation of these roads.

Heavy vehicle speed decreases as the load increases so the speed of traffic carried by the heavy vehicle overloading conditions lower than the speed of heavy vehicles with cargo load conditions according to the capacity. The linear regression equation velocity against overloading percentage is $\mathrm{y}=-11.018 \mathrm{x}+46.153$.

Heavy vehicle operating costs on the higher overloading conditions when compared to heavy vehicles with normal cargo loading conditions. Vehicle speed and vehicle weight are factors that influence differences in vehicle operating cost results overloading and normal payload.

Inability trucks running faster also besides affected overloaded vehicles but also affected the load ratio to the power of the engine horsepower (hp) as seen from the collection of data that under normal conditions or load truck $0 \%$ rate is still below the reference speed MKJI is $60 \mathrm{~km} / \mathrm{h}$.

\section{RECOMMENDATION}

The number of overloaded vehicles should be reduced because of a negative impact and significant impact on the traffic condition of these roads. Increasing the engine capacity of heavy vehicles from 220PS to 400PS so that the vehicle can reach the speed referred by MKJI.

Further research needs to be done by adding other variables as well as the progress of research in more detail so that the data and the resulting model is more accurate. 


\section{REFERENCES}

1. M. R. Karim, N. I. Ibrahim, A. A. Saifizul, and H. Yamanaka. Effectiveness of Vehicle Weight Enforcement in a Developing Country Using Weigh-In-Motion Sorting System Considering Vehicle By-Pass and Enforcement Capability, IATSS Research 37, pp. 124 - 129, 2014.

2. C. Molina. Development of Passenger Car Equivalencies for Large Trucks at Signalised Intersections, ITE Journal, 1987.

3. K. Fitzpatrick, D. Middleton, D. Jasek. Countermeasures for Truck Accidents on Urban Freeways: A Review of Experiences, Transportation Research Record, 1992.

4. P. Sweatman, K. Ogden. Urban Truck Crashes, Michigan Transportation Research Institute, 1995.

5. S. Moridpour, E. Mazloumi, and M. Mesbah. Impact of heavy vehicles on surrounding traffic characteristics, Journal of advanced transportation, vol. 49, no. 4, pp. 535-552, 2015.

6. J. Jihanny, B. S. Subagio, and E. S. Hariyadi. The analysis of overloaded trucks in indonesia based on https://doi.org/10.1002/atr.1286 weigh in motion data (east of sumatera national road case study), In MATEC Web of Conferences, vol. 147, p. 02006, 2018, EDP Sciences.

7. Delgado, A., Cueva-Ruiz, L. Design of a 3d control system using PTV-VISSIM to manage vehicle traffic, International Journal of Emerging Trends in Engineering Research 8(5), pp. 1819-1823, 2020. https://doi.org/10.30534/ijeter/2020/55852020

8. Shchypanskyi, P., Savchenko, V., Martyniuk, O., Kostiuk, I. Air defense planning from an impact of a group of unmanned aerial vehicles based on multi-agent modeling, International Journal of Emerging Trends in Engineering Research 8(4),59, pp. 1302-1308, 2020. https://doi.org/10.30534/ijeter/2020/59842020

9. Ibrahim, M.N., Siswanto, W.A., Zaidi, A.M.A. Numerical study of 2024 T3 aluminum plates subjected to impact and perforation, Journal of Mechanical Science and Technology, 28(11), pp. 4475-4482, 2014. 